Research Article

\title{
Evaluation Model of Cable Insulation Life Based on Improved Fuzzy Analytic Hierarchy Process
}

\author{
Lei Li $\mathbb{D}^{1},{ }^{1}$ Xian Min Ma, ${ }^{1}$ and Wei Guo $\mathbb{D}^{2}$ \\ ${ }^{1}$ College of Electrical and Control Engineering, Xi'an University of Science and Technology, Xi'an 710054, China \\ ${ }^{2}$ College of Mechanical Engineering, Xi'an University of Science and Technology, Xi'an 710054, China
}

Correspondence should be addressed to Lei Li; liqieru@xust.edu.cn

Received 17 December 2020; Revised 17 March 2021; Accepted 5 May 2021; Published 24 May 2021

Academic Editor: Ming Bao Cheng

Copyright (C) 2021 Lei Li et al. This is an open access article distributed under the Creative Commons Attribution License, which permits unrestricted use, distribution, and reproduction in any medium, provided the original work is properly cited.

Since the human society entered the electrification era, people's work, life, and even the production and development of various industries in society are inseparable from the supply of electricity. The purpose of this paper is to establish a cable insulation life evaluation model based on the improved fuzzy analytic hierarchy process to test the current insulation characteristics and life of various types of cables, so as to ensure the quality of power supply and safe production of power. This paper first understands the cable insulation characteristics test process and electrical power-related knowledge through a large number of literature studies and consultation with power grid professionals. Then this paper combines the theoretical research and improvement of the fuzzy analytic hierarchy process based on the actual situation of the cable insulation characteristics, thereby constructing the cable insulation life evaluation model. In this evaluation model, this paper combines the fuzzy comprehensive evaluation method and the analytic hierarchy process as well as the actual situation of the cable characteristic test to analyze and predict the insulation life of the cable. Finally, the linear test and reliability estimation of the experimental results are carried out, and the application of this evaluation model is extended to the evaluation of insulation life of other types of cables. Based on this, this paper proposes a cable insulation life evaluation model based on the improved fuzzy analytic hierarchy process. This model combines the Weibull model and the Arrhenius model commonly used in the assessment of cable insulation aging life and the improved fuzzy analytic hierarchy process. Experiments have proved that, within a certain range, temperature factors have a significant impact on the cable insulation life. For example, when the temperature is below $55^{\circ} \mathrm{C}$, the insulation life of the cable is usually 30 to 50 years. However, the evaluation model of the improved fuzzy analytic hierarchy process in this paper has much higher accuracy in evaluating cable insulation life than other life evaluation methods.

\section{Introduction}

1.1. Background and Significance. Electricity is the most important energy source for social production and development. Only a safe and stable electric power supply and a high-quality and reliable power supply environment can escort the vigorous development of production in various industries. The most important factor influencing power supply safety is the insulation characteristic life of the cable material. Testing the performance of the cable through scientific physical regulation and chemical reaction is a powerful measure to evaluate the life of the cable and improve the safety of the power supply [1]. Although the most important function of cables is to provide excellent conductors for power transmission, there are huge differences in the working environment of cables in different industries. In particular, temperature, humidity, electromagnetic fields, and other environmental factors have relatively high power supply performance and insulation life [2]. Therefore, in addition to the environmental external forces and various unexpected disasters, the evaluation of the insulation performance life of the cable itself is also extremely critical in the safeguard measures for the power supply safety environment. Studies have shown that the main influencing factor of cable insulation life is the process of cable aging, which is divided into electrical aging, thermal aging, water aging, and mechanical aging $[3,4]$. Because many companies often lead to overloaded operation of cables in the process of using cables for 
power supply, this easily accelerates the electrical aging process of the cables and shortens the insulation life of the cables $[5,6]$. In addition, changes in temperature and humidity in some special power supply production environments may also affect the thermal aging and water aging processes of the cable, which in turn affects the insulation life of the cable [7]. Therefore, this paper explores that the insulation life evaluation model of the cable should consider the insulation life test situation of the cable in various working environments as much as possible.

1.2. Related Research at Home and Abroad. Regarding the life evaluation of cable insulation aging, there have been quite indepth studies at home and abroad, and rich research results have been obtained. For example, Santhosh performs accelerated thermal and radiation aging on control cable insulation materials used in nuclear power plants and uses oxidation induction time (OIT) and oxidation induction temperature (OITp) to evaluate the degradation of cable insulation properties due to thermal and radiation aging. Studies have found that factors such as long-term exposure and temperature rise will eventually lead to a decline in cable insulation performance [8]. In order to study the life of the cable insulation, Kim has artificially aged the samples under multiple stresses of heat and electricity. The multistress aging samples were evaluated by measuring the pulse breakdown voltage at a high temperature of $85^{\circ} \mathrm{C}$. Experiments have shown that thermal aging will be regarded as one of the main factors in the life evaluation of cable insulation materials, while the effect of electrical degradation is poor [9]. However, the study did not explore the effect of humidity changes on the water aging of the cable. Seguchi et al. explain the evaluation behavior of XLPE insulation by using two popular evaluation methods, partial discharge (PD), and dielectric response (DR) measurements. For local evaluation, they proposed a comparative study of surface discharge and its characteristics under normal power frequency $(50 \mathrm{~Hz})$ and extremely low frequency $(0.1 \mathrm{~Hz})$ excitation [10]. However, the degradation of the cross-linked polyethylene (XLPE) insulated power cable material due to various factors during the experiment cannot be avoided. Hinderliter believes that the degradation of polymer sheaths and the potential for insulation of medium and low voltage power cables represent an extension of the life of nuclear power plants, and its mechanical understanding of the degradation process is essential to confidently predict the functional properties and safety margins of dielectrics. Studies have shown that the reduced exposure performance of cable sheaths and insulation materials in humid or immersed environments is due to their possible interaction with the pores in the polymer [11]. However, this study only explored the impact of medium and low voltage power on the life of cable insulation and did not make accurate assessments and corresponding improvement measures.

There are also important research conclusions on the assessment of cable insulation life in China. Studies have found that the long-term performance of cable insulation has been severely challenged by the technological advancement of high-voltage DC power lines for large-capacity long-distance submarine or underground transmission worldwide. In order to quantify the relationship between the applied stress (electrical, thermal, and mechanical stress) and the failure time (lifetime), Zuo et al. proposed several competing life expressions based on different mechanisms and the average life data through laboratory tests. The fitting model expression can compare the different durability characteristics of insulation material candidates and study their performance in a given cable system [12]. However, this expression still has certain limitations and has not been widely adopted. Su et al. used electrical tree testing to determine the withstand voltage coefficient of solid insulating materials. In the tree test with a needle-plane electrode system, the start-up time of the tree is measured under both progressive and constant voltage, and the residual voltage method is used to determine the withstand voltage coefficient [13]. However, the measured value is affected by the test conditions, and its effectiveness still needs further proof. Zhou et al. proposed a new method of online insulation dielectric loss monitoring based on insulation layer separation as an important index test method for cable insulation health [14]. However, there are still no reports of any successful online technology for this method. Chang et al. proposed a decision tree method for judging the initial and final stages of insulation degradation of preformed power cable joints with air gaps and void defects. Using cluster theory, this decision tree method is applied to evaluate the transition of insulation status. According to the Gini coefficient and information gain of the decision tree algorithm, the insulation state diagnosis rule is derived [15].

1.3. Innovations in This Paper. This paper studies the influence of the temperature and conductivity stress coefficient of the cable insulation material on the life and reliability of the cable and conducts the evaluation experiment of the cable insulation life based on the principle of the acceleration of electric thermal aging. On the basis of the balance between the content analysis and evaluation principles of the existing cable insulation life evaluation, a cable insulation life evaluation index system was established, and the insulation life evaluation was carried out using the fuzzy analytic hierarchy process $[16,17]$. Through the quantification process, the existing cable insulation characteristics are scientifically evaluated, and reference evaluation data are provided for the insulation characteristics of various types of cables under the influence of internal and external factors in different working environments $[18,19]$. This paper combines the advantages of the traditional analytic hierarchy process and fuzzy analytic hierarchy process to evaluate the insulation life of the cable from various influencing factors. Finally, based on the comprehensive analysis, the evaluation and prediction of the cable insulation life are given. The experiment shows that the evaluation result of this method is more accurate than other methods [20].

\section{Evaluation Model of Cable Insulation Life Based on Fuzzy Analytic Hierarchy Process}

2.1. Commonly Used Cable Insulation Aging Assessment Models. In the early days when cables were used in power 
supply environments, there was no standardized evaluation method for the insulation life of cables. At that time, electric power production enterprises all regulated the service life of cables based on practical experience and regular inspections. The insulation life of cables was basically the same as the service life of cables. Therefore, domestic and foreign electrical engineering scholars have carried out a large number of simulation experiments on cable insulation aging and proposed several standard cable insulation aging assessment methods. The most famous of them are the conventional evaluation method and the accelerated evaluation method. As the name suggests, the conventional evaluation method is to test the insulation aging life of conventional cables through sampling tests. However, the test cycle of this method is too long and the error is large, and it has been gradually eliminated [21]. This paper uses an accelerated assessment method and a series of cable insulation life assessment models. The commonly used insulation life assessment models for this method are the Weibull model and the Arrhenius model. The principle of the Weibull model is the theory of breaking down the weakest point of the cable insulation material to make the cable insulation failure. This theory is also called the "weakest ring principle" [22]. According to the characteristics of the cable insulation material, the Weibull model of the cable insulation breakdown can be obtained as shown in

$$
P(E, t)=1-e^{-c\left(E / E_{0}\right)^{\alpha}\left(t / t_{0}\right)^{\beta}} .
$$

In formula (1), $P$ is the probability that the cable insulation material will be broken down under the action of an electric field intensity of $E$ in time t. $\alpha$ and $\beta$, respectively, represent the relevant parameters of the probability density function of the cable insulation material breakdown, the breakdown electric field strength, and the action time. $c$ is the constant coefficient in the function, and $t_{0}$ represents the minimum expected value of the cable insulation life under the action of an electric field of $E_{0}$ intensity. Assuming that the electric field breakdown probability of the same cable insulation material is the same, the insulation aging life equation can be obtained as shown in

$$
\begin{aligned}
& C_{1}=1-e^{-c E^{\alpha} t^{\beta}}, \\
& C_{2}=E^{n} t, \quad n=\frac{\alpha}{\beta} .
\end{aligned}
$$

In formula (2), $C_{1}$ and $C_{2}$ are related constants, and $n$ represents the insulation aging life index. The value of the insulation aging life index can be calculated by simulating the relevant data of the cable insulation aging experiment, so as to obtain the evaluation value of the cable insulation life under different intensities. The above Weibull model is mainly aimed at the cable insulation life under the influence of electrical aging factors of the cable material. Another important factor affecting the aging of the cable insulation is thermal aging. The commonly used insulation life evaluation model is the Arrhenius model [23]. This model studies the relationship between temperature and the rate of chemical reaction of the cable insulation material. According to the chemical reaction kinetic curve, the Arrhenius equation for cable aging life evaluation can be obtained as shown in

$$
C(T)=k_{0} e^{-E_{\alpha} / R T} .
$$

In formula (3), $C(T)$ represents the chemical reaction rate constant of the cable insulation material, $k_{0}$ represents the prefactor of the chemical reaction, and $E_{\alpha}$ represents the activation energy of the chemical reaction, and its unit is kJ/ mol. $R$ and $T$ represent gas constant and thermodynamic temperature, respectively. The unit of gas constant is $\mathrm{J} /$ (K.mol), and the unit of thermodynamic temperature is $\mathrm{K}$. It is assumed that the cable insulation material reaches the same insulation failure standard under different thermodynamic temperatures and different chemical reaction rate constants. According to the chemical reaction kinetic curve model, the thermal aging life evaluation equation of the cable insulation chemical reaction can be obtained.

$$
\begin{gathered}
F(t)=k_{0} e^{-E_{\alpha} / R T}, \\
\ln t=k+\frac{E_{\alpha}}{R T} .
\end{gathered}
$$

In formula (4), $F(t)$ is the insulation failure standard achieved by the cable insulation under different chemical reaction times $t$, and $k$ is a constant coefficient related to the aging performance of the cable insulation. The Arrhenius model reflects the relationship between the aging life $t$ of the cable insulation material and the aging temperature $T$ and is a commonly used evaluation model in the accelerated evaluation experiment of the cable aging life evaluation.

2.2. Determine the Evaluation Index System of Cable Insulation Life. To establish a cable insulation life evaluation model based on fuzzy analytic hierarchy process, first determine the evaluation index system of cable insulation life. Then compare the relative importance of the indicators of each evaluation level of the model with the indicators of the previous level to determine the weight of the influencing factors of each level. This paper uses the judgment matrix to achieve this goal, that is, to evaluate the importance of a certain criterion level index defined in the cable insulation aging life assessment model to the target level index that needs to be analyzed and evaluated $[24,25]$. This hierarchical model of message evaluation is to compare the importance of indicators at the criterion level and the target level. In this paper, the importance of factors in the standard level is measured on a scale of 1-9. The comparison of the importance of the index system in this paper is shown in Table 1. According to the defined importance evaluation rules, the element values of the matrix are listed separately to obtain the judgment matrix. The singular grades ranging from grade 1 to grade 9 in the importance evaluation grades, namely, grades $1,3,5,7$, and 9 respectively, indicate that the former is more and more important to the latter. Levels 2, 4, 6 , and 8 represent the intermediate values of the adjacent evaluation levels corresponding to the above singular importance levels. 
TABLE 1: Analytic hierarchy process importance index.

\begin{tabular}{lc}
\hline Index value & Indicator meaning (compare two indicators) \\
\hline 1 & Have the same importance \\
3 & The former is slightly more important than the latter \\
5 & The former is fairly more important than the latter \\
7 & The former is especially more important than the latter \\
9 & The former is extremely more important than the latter \\
$2,4,6,8$ & The intermediate value of the above adjacent odd judgment \\
Reciprocal & The reciprocal of the above index indicates the importance of the latter to the former
\end{tabular}

According to the principle of the fuzzy analytic hierarchy process, this paper establishes a multilevel index system for cable insulation performance evaluation. The insulation performance of the cable is mainly reflected by the length of time the cable maintains its normal performance in the current working environment. This is also an important indicator for the evaluation of the cable insulation life. This paper divides the cable insulation performance into excellent, good, normal, poor, poor, and so on. Combining these five levels with the quantitative index standards of cable health value and then through the mapping relationship between the indicators, the following cable insulation evaluation index set can be obtained:

$$
V=\left(v_{1}, v_{2}, v_{3}, v_{4}, v_{5}\right)=(A, B, C, D, E) .
$$

In formula (5), $V$ represents the cable insulation performance evaluation score set, and the five elements in the evaluation score set represent five evaluation score levels of excellent, good, normal, poor, and poor. Then the mapping relationship between the vector composed of the evaluation score set and the evaluation matrix is shown in

$$
\mathrm{CCE}=V * C^{T}=f\left(x_{1}, x_{2}, x_{3}, x_{4}, x_{5}\right) .
$$

In formula (6), CCE is the English abbreviation for comprehensive evaluation of cables and is used here to express the comprehensive evaluation of cable insulation performance. $C^{T}$ represents the transposed matrix of the fuzzy comprehensive evaluation matrix. According to the fuzzy analytic hierarchy process and the evaluation matrix, the membership matrix can be further calculated. The membership degree matrix is often used in the comprehensive analysis of the indicators of the analytic hierarchy process. The maximum membership degree matrix is used to evaluate the index with higher performance as the trend of the evaluation index is larger. Conversely, the minimum membership degree matrix is used to evaluate the index with higher performance as the trend is smaller. Its evaluation principle is

$$
\phi(x)= \begin{cases}1, & x<\alpha, \\ \frac{x-\alpha}{\beta-\alpha}, & \alpha \leq x<\beta, \\ 0, & x \geq \beta .\end{cases}
$$

According to the characteristics of cable insulation aging life, this paper chooses the principle of maximum membership degree. Obviously, the larger the comprehensive evaluation index of the cable, the higher the insulation performance and the longer the insulation life. In formula (7), $\phi(x)$ represents the maximum membership function, and $\alpha$ and $\beta$ are the two critical levels of the comprehensive cable evaluation index.

2.3. Establish a Judgment Matrix and Calculate Indicator Weights. The evaluation of cable insulation life can start from the physical, chemical, and electrical properties of cable materials, which can extend 10 evaluation indexes of cable, such as dielectric loss, maximum internal electric field strength, impurity material, insulation resistance, insulation stress, insulation thickness, internal temperature, voltage load, external environment humidity, and elongation at break [26]. According to the evaluation index system of cable insulation life established above, a judgment matrix for the evaluation of cable insulation life is constructed.

$$
M=\left[\begin{array}{cccccc}
Y & A & B & C & D & E \\
a & x_{11} & x_{12} & x_{13} & x_{14} & x_{15} \\
b & x_{21} & x_{22} & x_{23} & x_{24} & x_{25} \\
c & x_{31} & x_{32} & x_{33} & x_{34} & x_{35} \\
\ldots & \ldots & \ldots & \ldots & \ldots & \cdots \\
g & x_{n 1} & x_{n 2} & x_{n 3} & x_{n 4} & x_{n 5}
\end{array}\right]\left[\begin{array}{c}
M i \\
m_{1} \\
m_{2} \\
m_{3} \\
\cdots \\
m_{n}
\end{array}\right]\left[\begin{array}{c}
V \\
v_{1} \\
v_{2} \\
v_{3} \\
\cdots \\
v_{n}
\end{array}\right]\left[\begin{array}{c}
W \\
w_{1} \\
w_{2} \\
w_{3} \\
\cdots \\
w_{n}
\end{array}\right]
$$

As shown in formula (8), matrix $M$ represents the importance judgment value of two insulation evaluation indicators compared with each other, wherein $x_{i j}$ represents the judgment value of the importance of the evaluation index $x_{i}$ and the evaluation index $x_{j}$ compared with each other. It should be noted that all elements in the judgment matrix should satisfy the condition that the sum is 1 . In the above judgment matrix, the left side is the importance level evaluation matrix of the criterion layer, $M i$ represents the product of each row element of the importance evaluation matrix, $v_{i}$ represents the value of the square root of each element in $M i$ according to the matrix order, and then $w_{i}$ represents the value of each element in $v_{i}$. The relevant calculation formula is as follows. The calculation formula for the value $M i$ of each row of the judgment matrix $M$ is shown in 


$$
M i=\prod_{j=1}^{n} x_{i j}, \quad i=1, \ldots, 6 .
$$

In formula (8), the calculation formula for the root value $v_{i}$ of each row of the target matrix is shown in formula (9), where $n$ represents the order of the judgment matrix. Accordingly, the value $w_{i}$ of each element of the weight matrix after the normalization of the target matrix can be further obtained.

$$
\begin{aligned}
v_{i} & =\sqrt[n]{M i}=\sqrt[6]{M i}, \\
w_{i} & =\frac{v_{i}}{\sum_{i=1}^{n} v_{i}}
\end{aligned}
$$

After calculating the weight of the cable insulation life evaluation index through the judgment matrix and the weight matrix, this paper conducts $C R$ verification on the cable insulation aging life evaluation model. The most important step of CR verification is the calculation of the consistency index $\mathrm{CI}$ and the consistency ratio $\mathrm{CR}$. The calculation of the consistency index must first be obtained by the maximum eigenvalue of the judgment matrix. The formula for calculating the maximum characteristic value $\lambda_{\max }$ is as follows:

$$
\lambda_{\max }=\sum_{i=1}^{n} \frac{(M * W)_{i}}{n W_{i}} .
$$

The consistency index CI of the matrix can be obtained by the maximum eigenvalue of the judgment matrix calculated in formula (11). According to the principle of consistency verification, when the consistency ratio is zero, the judgment matrix has complete consistency [27].

$$
\begin{aligned}
\mathrm{CI} & =\frac{\lambda_{\max }-n}{n-1}, \\
\mathrm{CR} & =\frac{\mathrm{CI}}{\mathrm{RI}} .
\end{aligned}
$$

From the above analysis, it can be seen that there are mainly 10 judgment indicators for the assessment of cable insulation aging life. According to the survey of the average random consistency index of the same order matrix in Table 2, the average random consistency index RI $=1.49$ of the tenth order matrix can be known, and the calculation formula of the consistency ratio CR of the evaluation matrix is shown in equation (12).

\subsection{Reliability Evaluation and Life Prediction of Cable} Insulation Aging. According to the cable insulation aging life evaluation model and accelerated evaluation method, the reliability evaluation and life prediction of the cable insulation aging characteristics are carried out in this paper. Studies have shown that, under the action of thermal stress, the life of the insulation material of the cable, which is the time to failure of the insulation characteristics, meets the Arrhenius equation. Combined with the study of the
TABLE 2: Average random consistency index of each order matrix.

\begin{tabular}{lcccccccccc}
\hline $\begin{array}{l}\text { Matrix } \\
\text { order }\end{array}$ & 1 & 2 & 3 & 4 & 5 & 6 & 7 & 8 & 9 & 10 \\
\hline RI & 0 & 0 & 0.58 & 0.89 & 1.12 & 1.24 & 1.32 & 1.41 & 1.45 & 1.49 \\
$\begin{array}{l}\text { Matrix } \\
\text { order }\end{array}$ & 11 & 12 & 13 & 14 & 15 & 16 & 17 & 18 & 19 & 20 \\
RI & 1.52 & 1.54 & 1.56 & 1.58 & 1.59 & 1.59 & 1.61 & 1.61 & 1.62 & 1.63 \\
\hline
\end{tabular}

influence of mechanical stress, the life equation of cable thermal aging, and mechanical aging can be obtained.

$$
L(T, s)=C \cdot e^{(A / T) s^{-m}}, \quad A=\frac{E_{\alpha}}{R} .
$$

In formula (13), $L$ is the inverse power law function of cable mechanical stress. $T$ is the thermodynamic temperature, $C$ is the constant determined by the actual aging test, and $A$ is the ratio parameter of the activation energy $E_{\alpha}$ of the cable aging reaction and the gas molecular constant $R . s$ represents the stress of the insulating material. According to the above formula, the insulation failure time under different temperature and material stress can be calculated.

$$
L=L_{0}\left(\frac{s}{s_{0}}\right)^{-m} e^{(\Delta E / C)\left((1 / T)-\left(1 / T_{0}\right)\right)} .
$$

Formula (14) expresses the cable insulation life under the conditions of temperature $T_{0}$ and material stress $s_{0}$, where $m$ is a constant and $\Delta E$ is the energy change in the aging reaction. According to the principle and process of cable degradation, the reliability of cable insulation materials can be evaluated through the cable insulation degradation equation.

$$
X(t)=\lambda t+\mu w(t)
$$

Equation (15) is the cable insulation degradation equation, where $X(t)$ represents the standard material insulation degradation process, which is regarded as a Brownian motion in chemistry, $\lambda$ represents the drift factor of Brownian motion, $\mu$ represents the diffusion factor, and $w(t)$ represents Brownian motion movement.

\section{Cable Insulation Life Evaluation Experiment}

3.1. Research Objects. The research object of this experiment is the evaluation of the insulation life of commonly used cables. According to related research, this paper establishes a cable insulation life evaluation model based on the improved fuzzy analytic hierarchy process as the evaluation method of cable insulation life. According to the fuzzy analytic hierarchy process and cable insulation life evaluation analysis, this paper established a three-level cable life evaluation index system. Among them, there are two primary indicators, namely, internal factors and external factors; secondary indicators are mainly three indicators of electrical performance, thermal performance, and mechanical performance under internal factors, and no secondary indicators are set under external factors; third-level indicators mainly include 10 factors, and the specific indicators are as described in the 
above analysis. According to the fuzzy analytic hierarchy process and improved, this paper will carry out analytic hierarchy through the experimental data of several life evaluation models, so as to achieve the purpose of evaluating and predicting the insulation life of cables. The index system structure of the cable insulation life assessment model is shown in Figure 1.

3.2. Experimental Design. The purpose of this experiment is to evaluate the insulation life of the cable. This paper selects the more commonly used cross-linked polyethylene (XLPE) cables and mine MYP cables for insulation aging life evaluation experiments. The experiment is mainly divided into five steps. The first step is to learn about the materials and characteristics of related types of cables through literature research and consultation with professionals to establish a cable insulation aging life evaluation index system. The second step is to build the experimental environment platform for this research in the physics laboratory, which mainly includes a vibration table, a voltage regulator, a transformer, and some temperature and humidity control devices. The third step is to simulate the actual working environment of the cable and accelerate the failure process of the cable insulation according to the electrical and thermal aging characteristics of the insulating material and record the relevant experimental data. The fourth step is to use the fuzzy analytic hierarchy process to analyze the cable insulation characteristic data recorded in the experiment to evaluate and predict the insulation life of the two types of cables. Finally, the linear test and reliability estimation of the experimental results are carried out, and the application of this evaluation model is extended to the evaluation of insulation life of other types of cables.

3.3. Test Results and Reliability Estimation. In order to analyze the performance of the cable insulation life evaluation model in this study, it is necessary to check the linearity of the data results of this experiment. The principle of the linear test is to carry out a linear test corresponding to a significant level of experimental data according to a certain confidence level of the standard confidence interval and compare the variance of the deviation from the linear regression equation with the total variance of the measured value to obtain the confidence level of the test data.

$$
\begin{aligned}
S^{2} & =\frac{\left[(N-m) s_{1}^{2}+(m-2) s_{2}^{2}\right]}{N-2}, \\
F & =\frac{s_{2}^{2}}{s_{1}^{2}} .
\end{aligned}
$$

Formula (16) is the estimated value of the joint variance of the experimental sample population data, where $s_{1}^{2}$ and $s_{2}^{2}$ represent the variance of the deviation of the data from the regression line and the variance of the sample population, $N$ represents the sample population, $m$ represents the sample data used for linearity test, and $F$ is the ratio of variance in the linearity test. Referring to the F value table of the standard confidence in probability statistics, the $t$ distribution value of the data can be obtained from the look-up table when the confidence is $95 \%$ and the significance level is 0.05 degrees of freedom, and the value conversion of the linear test of the data can be further calculated. Is the value $t_{\alpha}$ of the distribution of $t$, and the calculation formula is shown in

$$
t_{\alpha}=\left\{\frac{1}{t_{0.95, N-2}}-\frac{1-(N / m)}{(N /(N+1))+(N / 2)}\right\}^{-1} .
$$

\section{Discussion on Fuzzy Analytic Hierarchy Process Evaluation Model of Cable Insulation Life}

4.1. Mine MYP Cable Working Environment Detection. In order to study the insulation life of MYP cable for mine use, this paper conducted a chemical test on the environmental indicators of some mine cables. The main content of the test is the content of nitrogen, phosphorus, potassium, chlorine, calcium, and other elements. The working environment of the cable in the mine is generally buried in the soil. Therefore, it is also necessary to detect the $\mathrm{pH}$ value and the cation exchange capacity, that is, the hardness, humidity, and temperature in the soil. The test results are shown in Table 3. Among them, $\mathrm{N}$ refers to the nitrogen that can be used within a certain period of time, generally between 2 and $20(\mathrm{~g} / \mathrm{kg})$, which is at a low level. P content refers to the content of orthophosphate in the soil, usually between 5 and $50(\mathrm{~g} / \mathrm{kg})$, in a state of loss.

As shown in Figure 2, in the oxidation induction period curve of the cable insulation material in different working environments, the OIT of the XLPE sample after 2100 hours of electric and heating combined aging is extremely short, and the OIT of the new XLPE sample is 21 minutes. The oxidation induction period of the electric heating combined aging sample is shorter than the oxidation induction period of single thermal aging, indicating that the combined electric heating aging degree is serious, and the oxidation induction period is smaller. The OIT decreases significantly with the increase of the aging degree of the sample.

\subsection{Cable Structure and Insulation Material Performance} Parameter Analysis. After selecting the corresponding cable experimental sample materials, this paper investigates the insulation material properties and structural composition of the two types of cables. The results are shown in Table 4. Among them, the specific heat of the insulating layer reaches $640 \mathrm{~J} / \mathrm{kg}^{\circ} \mathrm{C}$, and the thermal conductivity is only 0.16 . It can be seen that the thermal conductivity of the insulating layer is the lowest among the cable constituent materials.

The material composition structure of the two types of cables is shown in Figure 3. The XLPE cable mainly includes conductor, inner semiconducting layer, insulating layer, inner lining, steel wire armor, outer semiconducting layer, and outer sheath. Mine MYP cable is mainly composed of copper core conductor, insulation layer, impurity layer, and rubber sheath. 


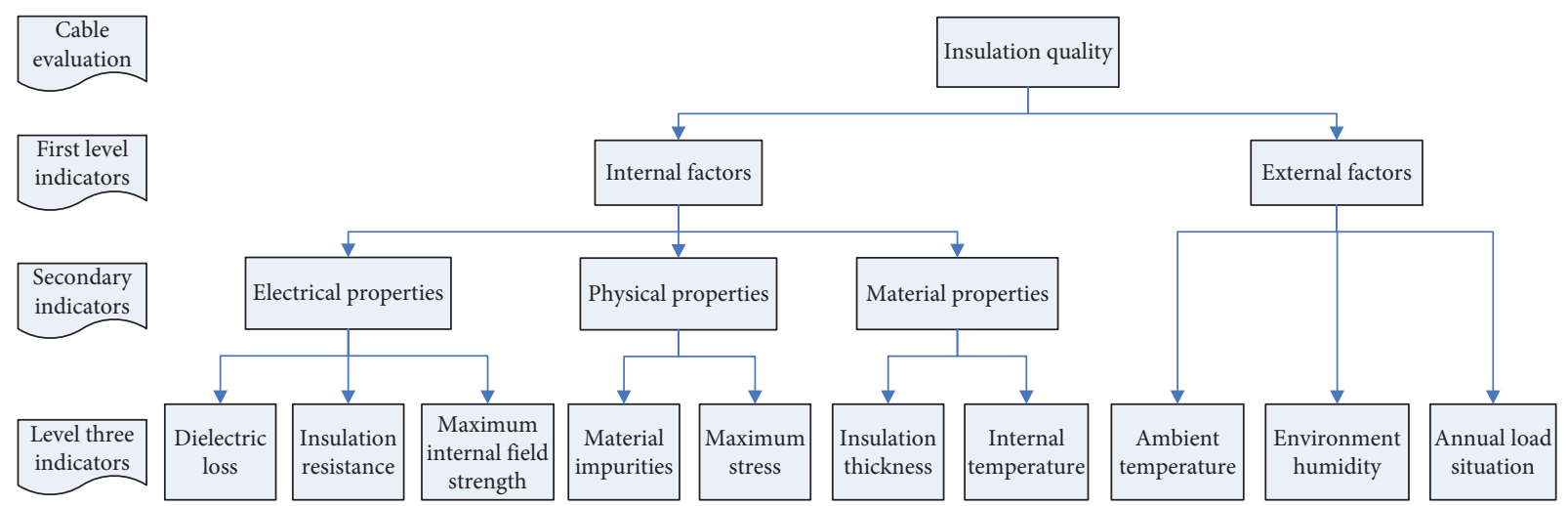

FIGURE 1: Cable insulation life evaluation system.

TABLE 3: MYP mining cable working environment chemical detection index.

\begin{tabular}{lccccc}
\hline Chemical index & $\mathrm{N}(\mathrm{g} / \mathrm{kg})$ & $\mathrm{P}(\mathrm{g} / \mathrm{kg})$ & $\mathrm{K}(\mathrm{g} / \mathrm{kg})$ & $\mathrm{Cl}(\mathrm{mmol} / \mathrm{L})$ & $\mathrm{Ca}(\mathrm{mmol} / \mathrm{L})$ \\
\hline Content & 3.43 & 3.67 & 11.46 & 234.65 & 1.37 \\
Chemical index & $\mathrm{PH}$ & Cation $(\mathrm{cmol} / \mathrm{kg})$ & Hardness $(\mathrm{mmol} / \mathrm{L})$ & Alkalinity $(\mathrm{mmol} / \mathrm{L})$ & $\mathrm{Conductance}(\mu \mathrm{s} / \mathrm{cm})$ \\
Content & 8.05 & 12.26 & 3.17 & 49.18 & 7.99 \\
\hline
\end{tabular}

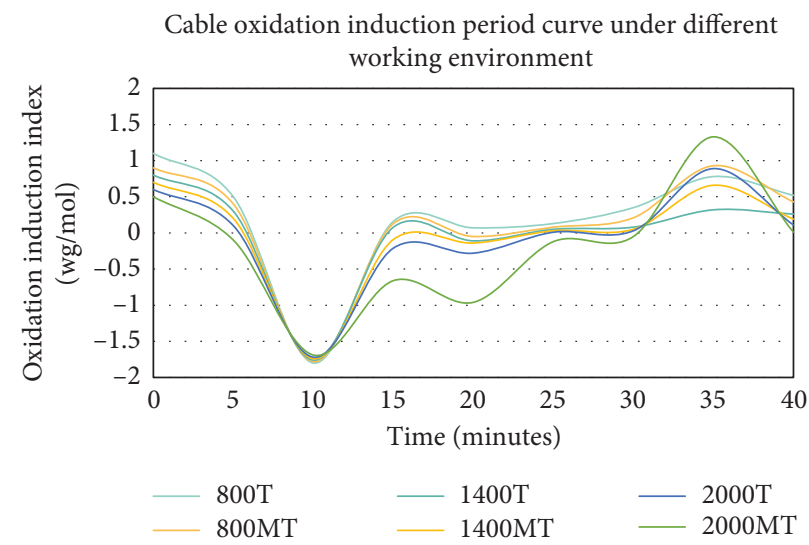

FIGURE 2: Cable oxidation induction period curve under different working environment.

TABLE 4: Cable structure and thermal performance parameters.

\begin{tabular}{lccc}
\hline Cable structure & Specific heat $\left(\mathrm{J} / \mathrm{kg}^{\circ} \mathrm{C}\right)$ & Thermal conductivity & Cable radius \\
\hline Large copper core & 385 & 106 & 3.8 \\
Small copper core & 385 & 106 & 2.5 \\
Neoprene sheath & 490 & 0.25 & 16.0 \\
Ethylene propylene rubber insulation & 640 & 0.16 & 5.0 \\
Other impurities & 475 & 49.07 & 2.3 \\
\hline
\end{tabular}

\subsection{Aging Data Indicators of the Cable at Different Temper-} atures and Electric Field Strengths. The change of cable insulation aging life with temperature and working voltage field strength is shown in Table 5. ICMT represents the highest temperature inside the cable, PAT represents the average temperature of the two phases, FMT represents the temperature of the filling material, and ICME represents the electric field strength inside the cable.

This experiment analyzes the insulation resistance and aging time under four-phase voltages, and the experimental 


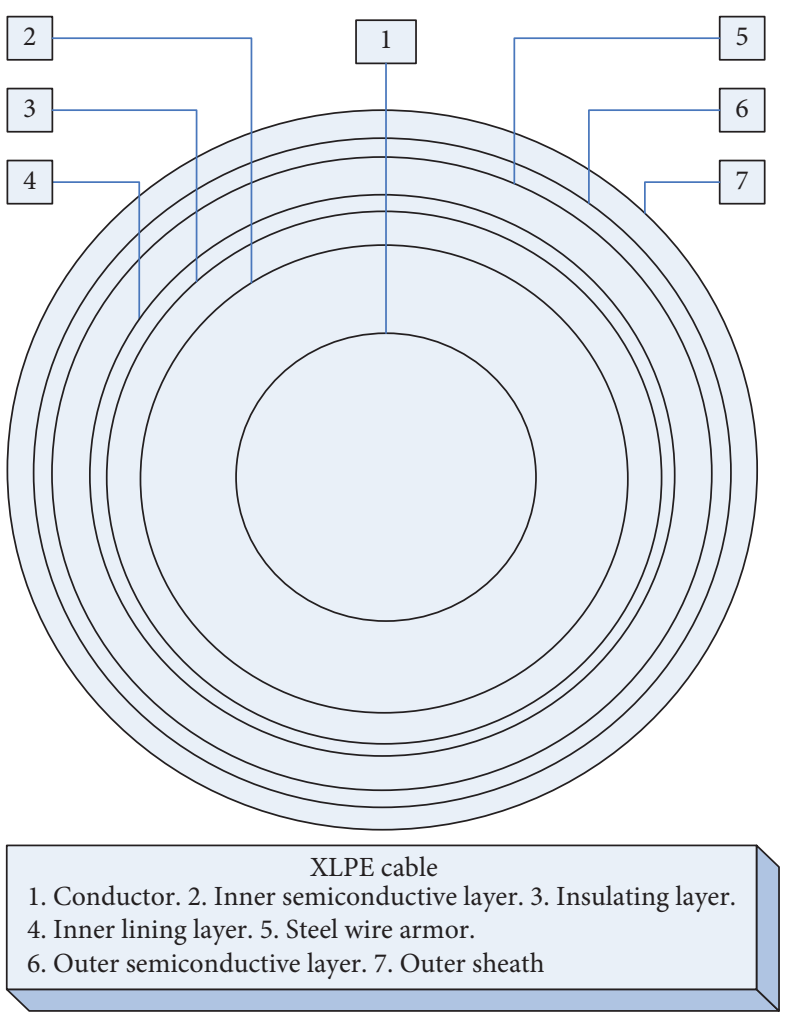

(a)

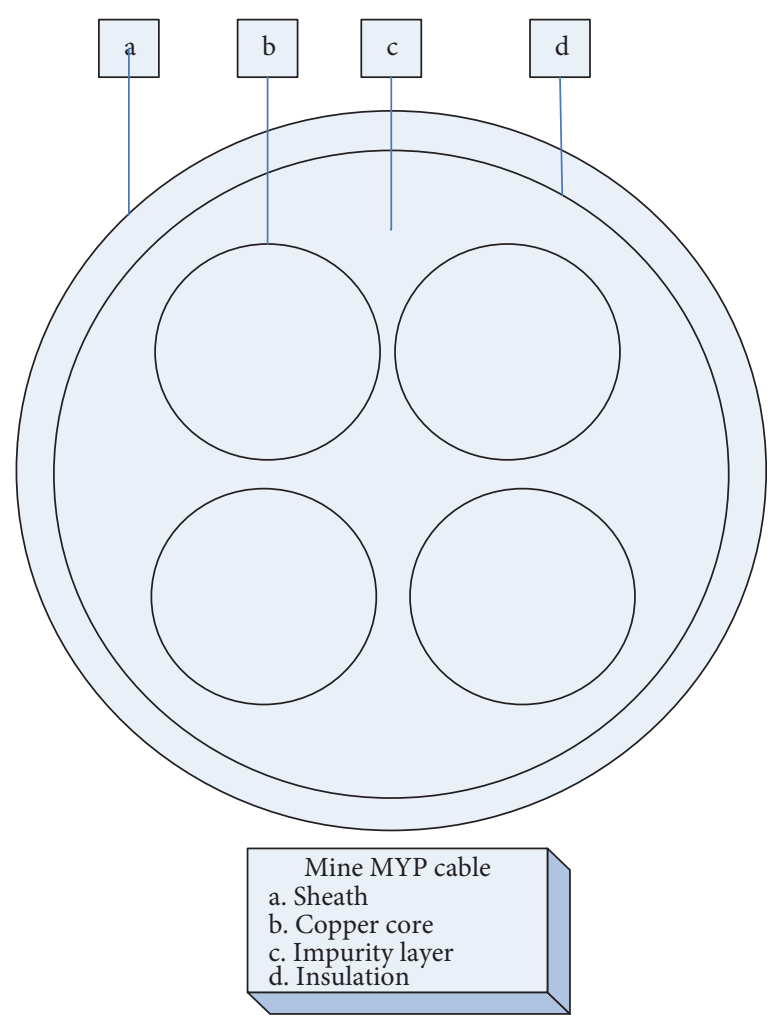

(b)

FIGURE 3: Material composition structure of (a) XLPE cable and (b) mine MYP cable.

TABLE 5: Changes of cable insulation aging temperature and electric field intensity.

\begin{tabular}{|c|c|c|c|c|c|}
\hline Impact index & Index value & ICMT & PAT & FMT & ICME \\
\hline \multirow{3}{*}{ Impurities and conductor spacing } & 2 & 51.64 & 47.75 & 43.66 & 5.47 \\
\hline & 3 & 51.38 & 47.22 & 43.93 & 5.06 \\
\hline & 4 & 50.49 & 47.16 & 44.17 & 4.65 \\
\hline \multirow{6}{*}{ Cable insulation performance loss } & Normal & 51.62 & 47.19 & 43.91 & 1.1476 \\
\hline & Loss $10 \%$ & 53.44 & 48.07 & 44.07 & 1.2064 \\
\hline & Loss $20 \%$ & 56.27 & 48.69 & 44.39 & 1.4142 \\
\hline & Loss $30 \%$ & 58.19 & 49.18 & 44.53 & 1.7643 \\
\hline & Loss $40 \%$ & 62.66 & 50.24 & 44.81 & 1.9065 \\
\hline & Loss $50 \%$ & 67.49 & 50.68 & 44.89 & 2.1421 \\
\hline
\end{tabular}

results are shown in Figure 4. Among them, the insulation resistance of phases $\mathrm{A}, \mathrm{B}$, and $\mathrm{C}$ is generally larger than that of phase $D$. This is because, during normal operation, the energizing current of phases $\mathrm{A}, \mathrm{B}$, and $\mathrm{C}$ during normal operation is much larger than that of phase $\mathrm{D}$, and phase $\mathrm{D}$ only has a certain current flow when the cable fails and the underground power system fails.

\subsection{Evaluation of Cable Insulation Aging Life under Different} Temperatures and Electric Field End Levels. Table 6 shows the aging life of cable insulation at different temperatures and end levels. It can be seen from the table that the aging life of the cable can reach 106 years in theory under 60 degrees Celsius and the key level of $40 \%$ of the electric field.
However, due to various factors in actual work, the insulation life of the cable is greatly reduced. The most influential factor is electricity.

Taking different end-point levels as the abscissa and the aging life of the cable at different end-point levels as the ordinate, the SPSS software is used to perform cubic polynomial fitting, and the curve of the aging time versus performance at each temperature of the cable is obtained. Take humidification as an example, as shown in Figure 5. According to the results of the aging experiment, the insulation life of the cable under the temperature environment of $60^{\circ} \mathrm{C}$ and below $60^{\circ} \mathrm{C}$ and the electric field environment with the end level of $40 \%$ and below can reach more than 106 years, but the actual cable working environment often cannot reach this level. 


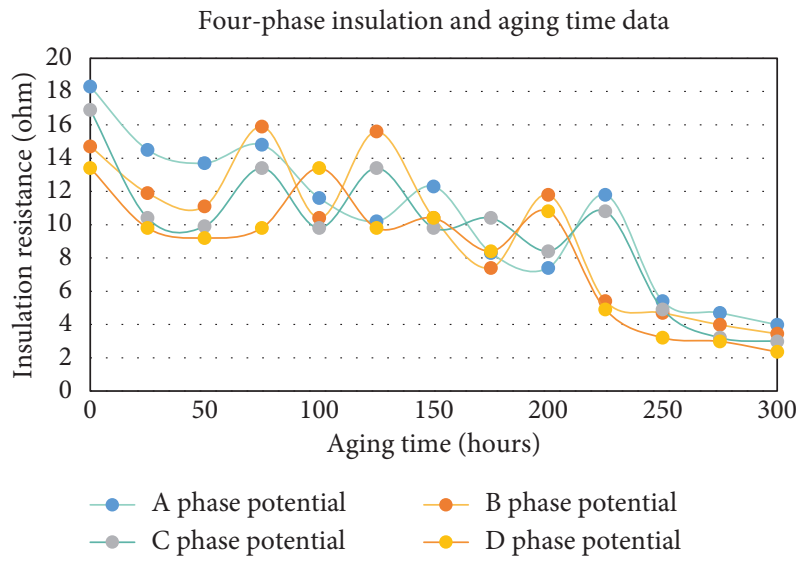

Figure 4: Four-phase insulation resistance and aging time data.

TABLe 6: Cable insulation aging life under different temperatures and end levels.

\begin{tabular}{lccccccccc}
\hline \multirow{2}{*}{ End level (\%) } & \multicolumn{9}{c}{ Aging life of cable insulation at different temperatures (years) } \\
& $60^{\circ} \mathrm{C}$ & $65^{\circ} \mathrm{C}$ & $70^{\circ} \mathrm{C}$ & $75^{\circ} \mathrm{C}$ & $80^{\circ} \mathrm{C}$ & $85^{\circ} \mathrm{C}$ & $90^{\circ} \mathrm{C}$ & $95^{\circ} \mathrm{C}$ & $100^{\circ} \mathrm{C}$ \\
\hline 40 & 106.2 & 99.6 & 73.4 & 61.3 & 30.8 & 13.9 & 8.3 & 4.7 & 1.9 \\
50 & 98.7 & 92.6 & 66.5 & 53.4 & 25.5 & 16.7 & 7.4 & 4.3 \\
60 & 89.9 & 83.3 & 42.3 & 37.4 & 21.2 & 14.2 & 6.1 & 3.8 & 1.3 \\
70 & 77.8 & 70.2 & 39.8 & 30.2 & 18.9 & 11.8 & 5.5 & 3.3 & 0.7 \\
\hline
\end{tabular}

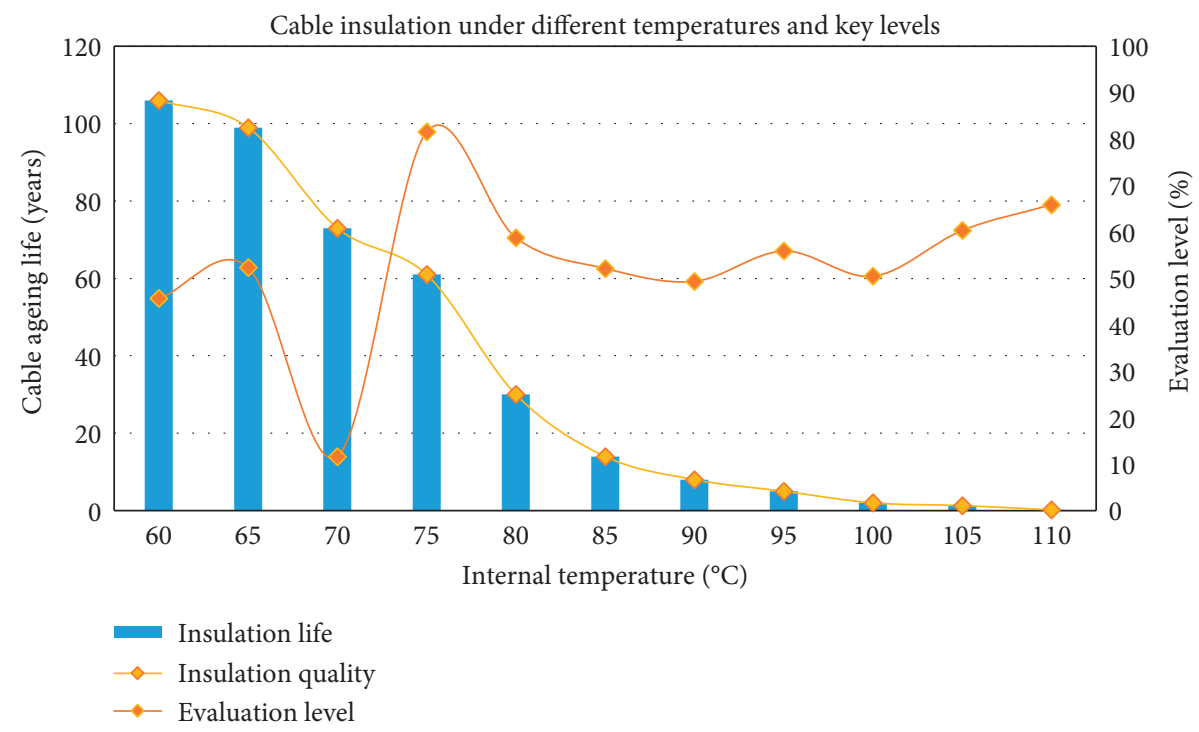

Figure 5: Cable insulation life under different temperatures and key levels.

\section{Conclusions}

This research mainly improves the fuzzy analytic hierarchy process for the evaluation of cable insulation life based on the cable insulation characteristics. In the investigation of current cable insulation aging life evaluation, this paper found that the current evaluation and prediction of cable insulation aging life are mainly evaluated by accelerated evaluation method and the principles of electrical aging and thermal aging. However, these evaluation models are highly pertinent and strongly dependent on the working environment of the cable. Based on this, this paper proposes a cable insulation life evaluation model based on the improved fuzzy analytic hierarchy process. This model combines the Weibull model and the Arrhenius model commonly used in the assessment of cable insulation aging life and the improved fuzzy analytic hierarchy process. It can evaluate the insulation life of cables in a more in-depth and more specific manner from the perspective of various influencing factors and provide companies and individuals using cables with 
more accurate cable life evaluation data, which reduces the resource consumption of power supply maintenance and improves the safety of the power supply.

The experiment in this paper adopts the accelerated thermal aging and electrical aging in the physical laboratory and the simulation experiment method of the cable working environment to conduct the insulation life of the crosslinked polyethylene cable (XLPE) and the mine mobile flexible cable (MYP) under the accelerated aging of electricity and heat. Under the influence of electrical and thermal aging, the time of cable insulation failure will be greatly shortened; that is to say, factors such as temperature and voltage will reduce the life of the cable insulation.

Due to the various types of cables, the production materials and structural specifications are different, and the performance analysis of the cable insulation life evaluation model in this study has certain limitations. It is hoped that, in the future, a more complete and better simulation effect of cable aging experiment platform can be established, and the cable insulation life evaluation model of this research can be extended to more types of cable insulation life evaluation applications.

\section{Data Availability}

No data were used to support this study.

\section{Conflicts of Interest}

The authors declare that they have no conflicts of interest.

\section{References}

[1] B. Diban and G. Mazzanti, "The effect of temperature and stress coefficients of electrical conductivity on the life of HVDC extruded cable insulation subjected to type test conditions," IEEE Transactions on Dielectrics and Electrical Insulation, vol. 27, no. 4, pp. 1313-1321, 2020.

[2] R. Hu, Z. X. Jing, Q. H. Wu, R. B. Yan, and Z. C. Cao, "Life cycle assessment of environmental impacts and total cost of power cable," Applied Mechanics and Materials, vol. 872, no. 9, pp. 412-419, 2017.

[3] T. V. Santhosh, A. K. Ghosh, B. G. Fernandes, and K. A. Dubey, "Performance assessment of I\&C cable insulation materials by DSC and SEM for NPP ageing management," International Journal of System Assurance Engineering and Management, vol. 7, no. 1, pp. 6-15, 2016.

[4] G. Mazzanti and M. Marzinotto, "Advanced electro-thermal life and reliability model for high voltage cable systems including accessories," IEEE Electrical Insulation Magazine, vol. 33, no. 3, pp. 17-25, 2017.

[5] L. Bessissa, L. Boukezzi, D. Mahi et al., "Lifetime estimation and diagnosis of XLPE used in HV insulation cables under thermal ageing: arithmetic sequences optimised by genetic algorithms approach," IET Generation Transmission \& Distribution, vol. 11, no. 10, pp. 2429-2437, 2016.

[6] W. Zuo, H. Yuan, Y. Shang, Y. Liu, and T. Chen, "Calculation of a health index of oil-paper transformers insulation with binary logistic regression," Mathematical Problems in Engineering, vol. 2016, Article ID 6069784, 9 pages, 2016.

[7] A. N. Jahromi, P. Pattabi, J. Densley, and L. Lamarre, "Medium voltage XLPE cable condition assessment using frequency domain spectroscopy," IEEE Electrical Insulation Magazine, vol. 36, no. 5, pp. 9-18, 2020.

[8] T. V. Santhosh, V. Gopika, A. K. Ghosh, B. G. Fernandes, and K. A. Dubey, "Reliability prediction of I\&C cable insulation materials by DSC and Weibull theory for probabilistic safety assessment of NPPs," Nuclear Engineering and Design, vol. 296, no. 1, pp. 51-61, 2016.

[9] J. Kim, W. Kim, H.-S. Park, and J.-W. Kang, "Lifetime assessment for oil-paper insulation using thermal and electrical multiple degradation," Journal of Electrical Engineering and Technology, vol. 12, no. 2, pp. 840-845, 2017.

[10] T. Seguchi, K. Tamura, H. Kudoh et al., "Degradation of cable insulation material by accelerated thermal radiation combined ageing," IEEE Transactions on Dielectrics \& Electrical Insulation, vol. 22, no. 6, pp. 3197-3206, 2016.

[11] B. Hinderliter, E. Hill, M. Maurer-Jones et al., "Cable insulation testing for mechanistic degradation FEA modeling," Transactions of the American Nuclear Society, vol. 118, no. 6, pp. 595-597, 2018.

[12] Z. Zuo, L. A. Dissado, C. Yao et al., "Modeling for life estimation of HVDC cable insulation based on small-size specimens," IEEE Electrical Insulation Magazine, vol. 36, no. 1, pp. 19-29, 2019.

[13] Y. Su, Y. Liu, and L. Zhong, "Evaluation of voltage endurance characteristics for new and aged XLPE cable insulation by electrical treeing test," IEEE Transactions on Dielectrics and Electrical Insulation, vol. 26, no. 1, pp. 72-80, 2019.

[14] C. Zhou, H. Yi, and X. Dong, "Review of recent research towards power cable life cycle management," High Voltage, vol. 2, no. 3, pp. 179-187, 2017.

[15] C.-K. Chang, C.-S. Lai, and R.-N. Wu, "Decision tree rules for insulation condition assessment of pre-molded power cable joints with artificial defects," IEEE Transactions on Dielectrics and Electrical Insulation, vol. 26, no. 5, pp. 1636-1644, 2019.

[16] T. V. Santhosh, V. Gopika, A. K. Ghosh, and B. G. Fernandes, "An approach for reliability prediction of instrumentation \& control cables by artificial neural networks and Weibull theory for probabilistic safety assessment of NPPs," Reliability Engineering \& System Safety, vol. 170, no. 2, pp. 31-44, 2018.

[17] W.-J. Kim, S.-H. Kim, D. G. Yang, H. Lee, J.-W. Cho, and H.-J. Kim, "Mechanical bending characteristics of HTS DC cable," IEEE Transactions on Applied Superconductivity, vol. 26, no. 4, pp. 1-4, 2016.

[18] J. L. Sohn, P. P. Kalbar, and M. Birkved, "Life cycle based dynamic assessment coupled with multiple criteria decision analysis: a case study of determining an optimal building insulation level," Journal of Cleaner Production, vol. 162, no. 9, pp. 449-457, 2017.

[19] I. Ahmadi-Joneidi, A. A. Shayegani-Akmal, and H. Mohseni, "Lifetime prediction of $20 \mathrm{kV}$ field-aged silicone rubber insulators via condition assessment," IEEE Transactions on Dielectrics and Electrical Insulation, vol. 24, no. 6, pp. 36123621, 2017.

[20] D. C. Morais, A. T. de Almeida, A. Teixeira et al., "PROMETHEE-ROC model for assessing the readiness of technology for generating energy," Mathematical Problems In Engineering, vol. 2015, Article ID 530615, 11 pages, 2015.

[21] A. Azadeh and S. Abdolhossein Zadeh, "An integrated fuzzy analytic hierarchy process and fuzzy multiple-criteria decision-making simulation approach for maintenance policy selection," Simulation, vol. 92, no. 1, pp. 3-18, 2016.

[22] M. Ashtiani and M. Abdollahi Azgomi, "Trust modeling based on a combination of fuzzy analytic hierarchy process and 
fuzzy VIKOR," Soft Computing, vol. 20, no. 1, pp. 399-421, 2016.

[23] S. Nazari, M. Fallah, H. Kazemipoor, and A. Salehipour, "A fuzzy inference-fuzzy analytic hierarchy process-based clinical decision support system for diagnosis of heart diseases," Expert Systems with Applications, vol. 95, no. 4, pp. 261-271, 2018.

[24] W. Chunsheng, L. Gaohuan, H. Chong et al., "Ecological vulnerability assessment based on fuzzy analytical method and analytic hierarchy process in yellow river delta," International Journal of Environmental Research and Public Health, vol. 15, no. 5, pp. 855-859, 2018.

[25] R. Aliyev, H. Temizkan, and R. Aliyev, "Fuzzy analytic hierarchy process-based multi-criteria decision making for universities ranking," Symmetry, vol. 12, no. 8, pp. 1351-1358, 2020.

[26] Y. A. Mowafi, T. Alaqarbeh, and R. Alazrai, "Putting context in the network access of mobile applications using fuzzy analytic hierarchy process," International Journal of Decision Support System Technology, vol. 11, no. 2, pp. 13-26, 2019.

[27] Q. Wang, W. Li, H. Yu et al., "Research on the application of evaluation method based on fuzzy analytic hierarchy process in emergency communication plans for power system," Dianli Xitong Baohu Yu Kongzhi/Power System Protection and Control, vol. 46, no. 22, pp. 171-177, 2018. 